INNOVACIÓN

\title{
A utilização do diário de bordo no processo de aprendizagem no curso de direito
}

\author{
La utilización de la bitácora en el proceso de aprendizaje en los cursos de derecho \\ The Use of the Logbook in the Law Process Learning Process
}

\author{
Luiz Alberto Pereira Ribeiro \\ Pontificia Universidad Católica de Paraná, Brasil
}

\begin{abstract}
RESUMO O objetivo do presente artigo é discorrer sobre o diário de bordo, bem como a sua utilização e a sua importância para a efetivação das metodologias ativas aplicada aos estudantes do curso de direito. Esse trabalho científico originou do projeto de formação docente conduzido pelo CrEAre (Centro de Ensino e Aprendizagem) da PUCPR, com apoio financeiro do projeto FINEP. As metodologias tradicionais estão sendo substituídas pelas metodologias ativas de ensino e o diário de bordo é um instrumento muito importante para a reflexão e a reorganização das atividades desenvolvidas em sala de aula aplicadas pelo professor, conforme será possível observar através da presente pesquisa.
\end{abstract}

PALAVRAS-CHAVE Educação, aprendizagem por competências, metodologias ativas, diário de bordo.

RESUMEN El propósito de este artículo es reflexionar sobre la utlización de la bitácora y su aporte como metodología activa utilizada por los estudiantes en los cursos de derecho. Esta experiencia de innovación se originó en un proyecto de formación docente dirigido por el Centro de Enseñanza y Aprendizaje de la PUCPR, con el apoyo del proyecto FINEP. Las metodologías tradicionales están siendo sustitudas por metodologías activas como la bitácura, que es un instrumento que aporta a la reflexión de la organización de las actividades aulicas que hace el docente.

PALABRAS CLAVE Educación, aprendizaje por competencias, metodologías activas, bitácora.

ABSTRACT This paper aims to discuss the logbook, its use and its importance for the realisation of active methodologies applied to law students. This scientific work orig- 
inated from the teacher training project conducted by PEAPR's CrEAre (Center for Teaching and Learning), with financial support from the FINEP project. Active teaching methodologies are replacing the traditional methodologies, and the logbook is a fundamental instrument for reflection and reorganisation of the classroom activities applied by the teacher, as will be observed through this research.

KEYWORDS Education, competency learning, active methodologies, logbook.

\section{Introdução}

As metodologias ativas têm ocupado, cada vez mais, um espaço muito importante no processo de aprendizagem, inclusive no curso de direito, motivo pelo qual o MEC incluiu nas Diretrizes Curriculares Nacionais, Resolução 5, de 17 de dezembro de 2018 CNE/CES - Marco Regulatório da Graduação em Direito - dentre os elementos estruturais do PPC «VI - modos de integração entre teoria e prática, especificando as metodologias ativas utilizadas».

Dentro desse contexto, para a efetiva utilização das metodologias ativas existem vários instrumentos que auxiliam nesse processo, dentre os quais destaca-se o «diário de bordo».

Assim, o objetivo do presente artigo é discorrer sobre o diário de bordo, bem como a sua utilização e a sua importância para a efetivação das metodologias ativas (estudo de casos e resolução de problemas) e na aprendizagem por competências aplicadas aos estudantes do $4^{\circ}$. Período do Curso de Direito, matutino, da PUCPR, Campus Londrina, no $2^{\circ}$. Semestre de 2018.

É importante destacar que esta pesquisa teve apoio financeiro do projeto FINEP e desenvolvida em um projeto de formação docente conduzido pelo CrEAre (Centro de Ensino e Aprendizagem) da PUCPR.

\section{Noções introdutórias}

Muito se tem discutido sobre o processo de aprendizagem no curso de direito, principalmente em decorrência das metodologias tradicionais utilizadas, particularmente as aulas expositivas e as aulas dialogadas.

No entanto, nos últimos anos, vivenciamos a utilização, em que pese de forma bem incipiente, a utilização por algumas universidades das metodologias ativas no processo de aprendizagem no curso de direito, com a finalidade de desenvolver as competências dos estudantes, como, por exemplo, a PUCPR (o CrEAre é o órgão responsável pela realização de oficinas, inclusive com o financiamento do FINEP e da PUCPR). 
Antes de definir metodologias ativas e diário de bordo, é necessário entender o que seja competência, haja vista que as metodologias ativas tem por objetivo desenvolver as competências dos estudantes com vistas ao saber ser, ser fazer e saber agir.

Na visão de Roegiers (2000: 82; Scallon, 2015) por competência é «a possibilidade, para um indivíduo, de mobilizar de maneira interiorizada um conjunto integrado de recursos em vista de resolver uma família de situações-problema».

Por conseguinte, Scallon (2015: 143-144) extraí as seguintes característica essenciais sobre a competência a partir de várias definições:

- A competência é uma capacidade, uma potencialidade (não observável) ou, ainda, uma característica permanente dos indivíduos. Um indivíduo é competente mesmo se estiver momentaneamente inativo. A competência se distingue, então, da noção de desempenho, que é sua manifestação concreta.

- A competência é a capacidade que uma pessoa tem de mobilizar ou mesmo utilizar com discernimento, seus próprios recursos ou outros exteriores.

- A mobilização desses recursos se faz de maneira interiorizada, segura, sem indecisão, sem hesitação.

- O indivíduo mobiliza um conjunto integrado de recursos, o que e diferente de uma simples adição ou justaposição de elementos.

- Esses recursos são constituídos de saberes, de saber-fazer e de saber-ser interiores ou exteriores ao sujeito.

- A competência é uma capacidade revelada quando a pessoa é colocada em uma família de situações-problema (várias tarefas complexas que apresentam semelhanças).

É importante compreender que se objetivamos que os nossos estudantes de direito estejam aptos a serem verdadeiros operadores do direito («saber», «saber fazer», «saber agir»), a utilização das metodologias ativas se torna instrumento imprescindível nesse processo de aprendizagem por competências.

Os métodos tradicionais («de superfície»), que privilegiam a transmissão de informações pelos professores, não objetivam desenvolver a competência «do saber fazer», estimulando os níveis mais baixos de conhecimento na taxonomia de Bloom (conhecimento e compreensão).

Em contrapartida as metodologias ativas sob o enfoque do desenvolvimento das competências dos estudantes estimulam a autonomia, o pensamento crítico e reflexivo, a criatividade, a inovação, auxiliando os alunos a aprenderem melhor, a desenvolverem as suas aptidões e, por conseguinte, serem competentes profissionalmente.

No método tradicional os estudantes possuem postura passiva de recepção de teorias, ao contrário do método ativo, posto que estes passam a ser «compreendidos 
como sujeitos históricos e, portanto, a assumir um papel ativo na aprendizagem, posto que têm suas experiências, saberes e opiniões valorizadas como ponto de partida para construção do conhecimento» (Diesel, Santos Baldez, Neumann Martins, 2017).

Uma educação, principalmente na Universidade, «que não seja desafiadora, que não se proponha a formar iniciativas, que não prepare para a mobilização, que não instrumente a mudança, que não seja emancipatória, é mera fábrica de repetição das formas de ação já conhecidas» (Bittar, 2007).

Nesse sentido, Vosgerau, Oliveira, Spricigo e Martins (2017) ensinam:

Dos estudantes e egressos das instituições de ensino superior, espera-se a capacidade de somar competências técnicas e humanas a fim de promover a verdadeira emancipação, por meio dos aparatos tecnológicos (ou seja, aproveitando-se deles como instrumentos e não como fins em si mesmos) e de metodologias de ensino e aprendizagem focadas na interação, na solução de problemas complexos, no desenvolvimento de competências e habilidades múltiplas, como a compreensão mútua, a comunicação oral e escrita, o trabalho em equipe, a liderança democrática e participativa, o empreendedorismo, a inovação, a atitude ética, a consciência comunitária, ambiental, ecológica e afetiva, entre outras. Tais demandas passam a exigir da universidade uma atualização dos currículos e das metodologias, visando enriquecer a experiência do estudante no ambiente universitário e garantir a empregabilidade e a qualificada atuação profissional e cidadã.

Nesse contexto, é indiscutível a importância das metodologias ativas, posto que são voltadas para a aprendizagem, consistindo em um conjunto de técnicas, procedimentos e processos utilizados pelos professores, antes, durante e depois das aulas, procurando criar situações de aprendizagem, nas quais os estudantes possam saber fazer, pensar e conceituar o que fazem, construindo conhecimentos sobre os conteúdos envolvidos nas atividades que realizam, bem como desenvolvendo a capacidade crítica (refletir sobre as práticas realizadas), fornecendo e recebendo feedback, aprendendo a interagir com os demais estudantes e com o professor, explorando atitudes e valores pessoais (Valente, 2018).

Assim, as estratégias pedagógicas precisam acompanhar os objetivos pretendidos. Se quisermos que os estudantes sejam proativos, precisamos adotar metodologias em que os estudantes se envolvam em atividades cada vez mais complexas, em que tenham que tomar decisões e avaliar os resultados com o apoio de materiais relevantes (Oliveira, Gerevini e Strohschoen, 2017).

Dentre as técnicas utilizadas temos o diário de bordo, objeto desse artigo, que foi utilizado no processo de aprendizagem dos estudantes do $4^{\circ}$. período (matutino) do curso de direito da PUCPR, campus Londrina/PR, no segundo semestre de 2018, na disciplina de direito processual civil - recursos, que será objeto de estudo no próximo capítulo. 
Antes, porém, se faz necessário compreender o que seja «diário de bordo» e qual é a sua importância nas metodologias ativas e, por conseguinte, no processo de aprendizagem por competências.

O diário de bordo, também denominado como diário de aula, é um instrumento que permite que ao professor refletir sobre a prática educativa, refletindo sobre o seu plano de aula, descrevendo a dinâmica da sala de aula, através de registros sistemáticos e detalhados dos acontecimentos ocorridos (Porlán e Martín, 1997).

A partir do diário de bordo é possível o professor constatar os problemas enfrentados pelos estudantes e pelo próprio professor no processo de aprendizagem por competências e na utilização das metodologias ativas, possibilitando a adequação e a correção no processo de aprendizagem.

\section{O uso do diário de bordo nas metodologias ativas no processo de aprendizagem por competência dos estudantes do curso de direito na disciplina de direito processual civil - recursos}

O Projeto-Piloto de Inovação na Graduação - Projeto FINEP 3, projeto de formação docente conduzido pelo CrEAre (Centro de Ensino e Aprendizagem) da PUCPR, faz parte do programa de desenvolvimento da aprendizagem por competências institucionalizado pela PUCPR, com o objetivo de apoio, cooperação e interação entre professores para criação, desenvolvimento e difusão do conhecimento didático-pedagógico por meio de formação continuada, acompanhamento e incentivo de práticas que estimulem o protagonismo dos estudantes no desenvolvimento de competências profissionais, pessoais e sociais.

Dentro desse projeto, a disciplina de direito processual civil - recursos, ministrada para os estudantes do $4^{\circ}$. período, matutino, do curso de direito, foi escolhida para participar do respectivo projeto.

Foram realizadas várias oficinais de formação com ênfase nas metodologias ativas e no processo de aprendizagem por competências, estabelecendo como instrumento imprescindível na verificação da utilização das metodologias ativas e nos resultados do processo de aprendizagem o diário de bordo.

Definição do diário de bordo (diário de aula) e sua importância nas metodologias ativas

Os diários de bordo, ou também conhecido como diários de aula, podem ser definidos como documentos utilizados pelos professores para anotarem as suas impressões sobre o que ocorrem em suas aulas (Zabalza, 2007: 13).

O diário de bordo é visto como um instrumento que permite ao professor investigar e refletir sobre a prática educativa (plano de ensino e suas ações educativas) (Por- 
lán e Martín, 1997), ou seja, uma espécie de guia, onde é possível voltar aos registros para rever o que foi realizado (Oliveira, 2014) e repensar para a aplicação futura.

Zabalza (2007: 15) destaca duas variáveis básicas de diários (a riqueza informativa e a sistematicidade das observações recolhidas):

\section{A riqueza informativa que o diário apresenta.}

Um diário vai ser tanto mais rico quanto mais polivalente for a informação que se oferece nele. Os diários apenas introspectivos perdem sentido ao ficar estabelecido o ponto de referência externo em que os fatos ou as vivencias narrados acontecem.

O bom de um diário, o que se torna um importante documento para o desenvolvimento pessoal, é que nele se possa contrastar tanto o objetivo-descritivo como o reflexivo-pessoal.

A sistematicidade das observações recolhidas.

A principal contribuição dos diários em relação a outros instrumentos de observação é que permitem fazer uma leitura diacrónica sobre os acontecimentos. Com isso, torna-se possível analisar a evolução dos fatos.

Por conseguinte, na visão do referido autor, o diário de bordo (aula) pode ter uma finalidade mais investigativa (recurso destinado a incrementar o conhecimento disponível no campo da educação), como uma finalidade mais orientada para o desenvolvimento pessoal e profissional dos professores; tendo um impacto em quatro âmbitos (figura 1): acesso ao mundo pessoal, explicitar os próprios dilemas, avaliação

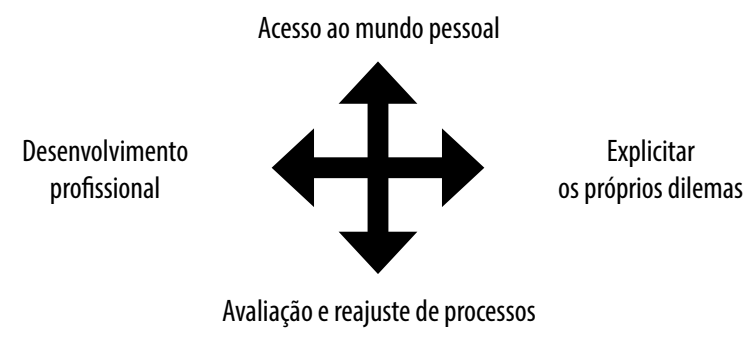

Figura 1. Visão diário de bordo.

e reajuste de processos e desenvolvimento profissional (Zabalza, 2007, 16)

O diário de bordo tem um importante papel no processo de aprendizagem e, principalmente, em relação a efetiva utilização das metodologias ativas, a fim de verificar se o processo de aprendizagem, dentro dos resultados de aprendizagem almejados (RA), está sendo alcançado, e se as metodologias ativas estão sendo utilizadas de forma adequada com o objetivo colimado de desenvolver nos estudantes as competências desejadas. 


\section{Elaboração do Diário de Bordo pelo CrEAre}

O CrEAre (Centro de Ensino e Aprendizagem) da PUCPR elaborou um roteiro do diário de bordo que foi utilizado em sala de aula para os estudantes do $4^{\circ}$. Período do curso de direito da PUCPR, campus Londrina, no $2^{\circ}$. Semestre de 2018.

O roteiro do diário de bordo elaboração pelo CrEAre foi dividido em várias perguntas, descrevendo as atividades desenvolvidas em sala de aula, bem como o planejamento de aula, os RAs, o feedback e a reflexão e reajustes na aplicação das metodologias e no processo de aprendizagem.

Diário de Bordo

Encontro (data):

O que eu planejei alcançar nesta aula e como planejei alcançar estes resultados? R: ...

Analisando meu discurso na resposta anterior: quais as lacunas ficaram entre o que eu pensei/fiz/disse/agir? O que fiquei surpreso (a) em descobrir?

R: ...

O que eu aprendi sobre mim mesmo, meus estudantes e sobre ensino e aprendizagem?

$\mathrm{R}: \ldots$

Analisando minhas respostas anteriores, quais os meus pontos fortes são revelados no meu discurso?

R: ...

O que eu gostaria de mudar no discurso sobre minha sala de aula e como farei estas mudanças no futuro?

$\mathrm{R}: \ldots$

O modelo apresentado pelo CrEAre procura enfatizar o impacto nos 4 âmbitos anteriormente informados: acesso ao mundo pessoal, explicitar os próprios dilemas, avaliação e reajuste de processos e desenvolvimento profissional.

\section{Da Aplicação do Diário de Bordo na Disciplina de Direito Processual}

Antes de apresentar o procedimento de aplicação do diário de bordo na referida disciplina, bem como os respectivos resultados obtidos, é necessário trazer algumas informações importantes sobre a respectiva disciplina.

\section{Informações importantes}

A disciplina de direito processual civil - recursos - ministrada para os estudantes do $4^{\circ}$. Período, matutino, $2^{\circ}$. Semestre de 2018 , do curso de direito, turma «A» (37 estudantes) e turma «B» (55 estudantes), disciplina semestral, possuía dois encontros 
semanais, totalizando uma carga horária semanal de 4 horas/aula e 80 horas/aula (6o horas/relógio) - semestral.

Trata-se de uma disciplina de "formação técnico-jurídica» («que abrange, além do enfoque dogmático, o conhecimento e a aplicação») e de «formação prático-profissional» (objetiva a integração entre a prática e os conteúdos teóricos desenvolvidos nas demais perspectivas formativas, especialmente nas atividades relacionadas com a prática jurídica e o TC).

O diário de bordo foi utilizado como instrumento no processo de aprendizagem por competências em relação as duas turmas do $4^{\circ}$. Período, destaca-se a utilização das seguintes metodologias ativas: aprendizagem baseadas em problemas, estudo de casos e aprendizagem entre pares ou times.

É importante destacar que as respectivas turmas contavam com dois monitores cada, sendo que um desenvolvia junto com o professor as atividades em sala e o outro desenvolvia atividades extraclasses, inclusive com a realização de grupo de estudo.

Antes de utilizar o diário de bordo e as metodologias ativas escolhidas, foi aplicado no primeiro dia de aula um questionário diagnóstico aos estudantes para verificar vários aspectos: conhecimento até aquele momento de temas de estudo, quantas horas de estudo por semana, quais as formas que o estudante entende que aprende melhor (estudar em casa, assistir a aula, estudar em casa e assistir a aula) e a complexidade da disciplina de direito processual civil.

\section{Do procedimento de aplicação do diário de bordo em sala de aula}

Como já informado anteriormente a disciplina de direito processual civil - recursos - possuiu uma carga horária semanal de 4 horas aula. No $2^{\circ}$. Semestre de 2018 foram realizados 35 encontros, sendo que desses 35 encontros 3 encontros foram utilizados para aplicação de avaliação somativa.

É importante ressaltar que não somente o professor elaborava o diário de bordo, mas, também, o monitor que estava em sala de aula junto com o professor.

Em relação ao monitor a confecção do diário de bordo se dava no transcorrer da aula e, posteriormente, era apresentado ao professor da disciplina para a respectiva análise.

Em relação ao professor da disciplina, a confecção do diário de bordo ocorria após o término da aula, seguindo o roteiro elaborado pelo CrEAre.

Para melhor elucidação, transcreve-se o diário de bordo do $2^{\circ}$. Encontro (2 de agosto de 2018) aplicado para o $4^{\circ}$. Período, turma B:

Encontro 2: dia 02 de agosto de 2018

O que eu planejei alcançar nesta aula e como planejei alcançar estes resultados?

$\mathrm{R}$ : Eu planejei a elaboração pelos estudantes de um mapa mental sobre o processo desde a petição inicial até a sentença (o que foi objeto de estudo nos períodos ante- 
riores nas disciplinas de processo civil). O planejamento iniciou com a apresentação da proposta de elaboração do mapa mental, o que foi aceito pelos estudantes. Os estudantes se reuniram em grupos de 5 , foi entregue aos estudantes papel Kraft e pincéis. Os estudantes, nos grupos, discutiram como elaborar o mapa mental. Eu caminhei na sala, entre as mesas (sala FINEP) observando. Após a elaboração, os estudantes pregaram os seus mapas mentais por toda a sala. Após, pedi para todos os estudantes que percorressem a sala de aula para observarem os mapas mentais dos outros grupos. Em decorrência do tempo, não tivemos a oportunidade de apresentação dos mapas mentais pelos grupos.

Analisando meu discurso na resposta anterior: quais as lacunas ficaram entre o que eu pensei/fiz/disse/agi? O que fiquei surpreso(a) em descobrir?

R: Entendo que deveria ter planejado um pouco mais o tempo para possibilitar apresentação dos mapas mentais dos grupos pelos estudantes. Dois pontos me deixaram surpreso e satisfeito. Primeiro a criatividade dos estudantes na elaboração dos mapas mentais. Segundo a participação de todos na elaboração dos mapas mentais.

$\mathrm{O}$ que eu aprendi sobre mim mesmo, meus estudantes e sobre ensino e aprendizagem?

R: Que preciso preparar melhor o tempo das atividades. Em relação aos estudantes eu aprendi que os mesmos se interagem e colaboram dentro do grupo, uns com os outros, para atingir o objetivo desejado. Que as metodologias ativas, com a utilização de elaboração de mapas mentais, aprendizagem colaborativa foram muito importantes para o processo de aprendizagem.

Analisando minhas respostas anteriores, quais os meus pontos fortes são revelados no meu discurso?

R: incentivar os estudantes a participarem do processo de aprendizagem. Responder as indagações incentivando os estudantes a pensarem e a discutirem.

$\mathrm{O}$ que eu gostaria de mudar no discurso sobre minha sala de aula e como farei estas mudanças no futuro?

R.: Preparar melhor o tempo para possibilitar que os estudantes possam apresentar os mapas mentais por eles elaborados.

Reitera-se que em todos os demais encontros (32) foram elaborados os diários de bordo, tanto pelo professor como pelo monitor.

Dos resultados obtidos na aplicação do diário de bordo aos estudantes do curso dedDireito e sua importância na aplicação das metodologias ativas no processo de aprendizagem por competências

No decorrer das aulas, bem como ao final do semestre foi possível constatar resultados interessantes em relação a aplicação do diário de bordo na disciplina de direito processual civil - recursos $-2^{\circ}$. Semestre de 2018 , do $4^{\circ}$. Período (matutino) do curso de direito da PUCPR, campus Londrina/PR. 
Para uma melhor compreensão a respeito se faz necessário dividir os resultados constatados em relação as seguintes rubricas:

a) Em relação as metodologias ativas aplicadas e em relação a aprendizagem por competências. A utilização do diário de bordo possibilitou a verificação da utilização das metodologias ativas, como foram aplicadas e os resultados da sua aplicação.

Por diversas vezes, o planejamento em relação a aplicação de determinada metodologia ativa com vistas a aprendizagem por competências não saia da forma esperada, motivo pelo qual com a elaboração do diário de bordo possibilitou refletir e reorientar com o objetivo de aplicar de forma adequada as metodologias ativas e, por conseguinte, aproximar dos resultados almejados, desenvolvendo as habilidades dos estudantes a fim de atingir as competências necessárias.

Ao responder aos questionamentos do diário de bordo ( $«$ o que eu planejei alcançar nesta aula e como planejei alcançar estes resultados?», «analisando meu discurso na resposta anterior: quais as lacunas ficaram entre o que eu pensei/fiz/disse/ agir? O que fiquei surpreso em descobrir?» e «o que eu gostaria de mudar no discurso sobre minha sala de aula e como farei estas mudanças no futuro?») possibilitava, ao final de cada aula, a verificação quanto aos resultados almejados a partir das metodologias ativas e um repensar, a cada aula, aproximando o discurso a prática, $\mathrm{o}$ «saber ser» e o «saber agir».

b) Em relação ao professor e os estudantes. O diário de bordo permitiu ao professor repensar a sua aula, as metodologias utilizadas, a todo momento, bem como perceber como os estudantes se comportam em sala, como desenvolvem as suas habilidades e como trabalham em grupos.

Da mesma forma, permitiu ao professor observar a necessidade incentivar os estudantes a participar em sala de aula dos grupos, das discussões, de se expressarem, de incentivar os estudantes a resolverem os problemas e os casos apresentados.

Duas questões do diário de bordo foram importantes para fazer a análise em relação ao professor e os estudantes quanto a aplicação das metodologias ativas: «O que eu aprendi sobre mim mesmo, meus estudantes e sobre ensino e aprendizagem?» e "Analisando minhas respostas anteriores, quais os meus pontos fortes são revelados no meu discurso?».

Para melhor compreensão, transcrevemos parte do diário de bordo:

O que eu aprendi sobre mim mesmo, meus estudantes e sobre ensino e aprendizagem?

R: que exige muito mais do professor e dos estudantes a utilização das metodologias ativas de aprendizagem, mas o resultado é muito melhor, desde que os estudantes compreendam a importância do processo de aprendizagem.

Analisando minhas respostas anteriores, quais os meus pontos fortes são revelados no meu discurso? R: incentivar os estudantes a participar do processo de aprendizagem. Responder as indagações incentivando os estudantes a pensarem e a discutirem. 
Zabalza (2007) enfatiza que descrever as ações realizadas proporciona uma reflexão da prática e, por conseguinte, dos detalhes relevantes para a prática docente.

Desta forma, observa-se que diário de bordo possibilita ao professor refletir e reorganizar as suas atividades com o objetivo de desenvolver as competências dos estudantes.

\section{Notas conclusivas}

No contexto atual as metodologias tradicionais estão sendo substituídas pelas metodologias ativas, estas voltadas para o estudando como centro no processo de aprendizagem, incentivando a participação dos estudantes com vistas a desenvolverem as suas habilidades com o intuito no desenvolvimento das suas competências.

Dentre as várias ferramentas utilizadas, o diário de bordo é uma ferramenta importante para a efetivação das metodologias ativas de aprendizagem, posto que permite, a partir de uma narrativa (diário de bordo) verificar as dificuldades enfrentadas no processo de aplicação das metodologias ativas.

Da mesma forma, permite ao professor corrigir eventuais erros no processo de aprendizagem, comparando entre os resultados esperado e os resultados obtidos, bem como preparar melhor as suas atividades a partir das anotações descritivas dos estudantes nos diários de bordo, possibilitando uma melhoria no processo de aprendizagem e, por conseguinte, uma melhor formação dos estudantes do curso de direito.

Em suma, o diário de bordo é um instrumento muito importante no processo de aprendizagem, pois além de descrever as atividades realizadas pelas estudantes, as impressões do professor sobre o processo de aprendizagem, permite, a todo momento, uma reflexão e uma reorientação nas atividades aplicadas pelo professor dentro da sala de aula com vistas a melhoria no processo de aprendizagem.

\section{Referências}

BItTAR, Eduardo Carlos Bianca (2007). Crise da ideologia positivista: Por um paradígma pedagógico par ao ensino jurídico a partir da Escola de Frankfurt [Resumo]. Anais. Florianópolis: Fundação Boiteux.

Diesel, Aline, Alda Leila Santos Baldez e Silvana Neumann Martins (2017). «Os princípios das metodologias ativas de ensino: uma abordagem teórica». Revista Thema, (14) 1: 268-288. Disponível em http://periodicos.ifsul.edu.br/index.php/ thema/article/view/404.

Oliveira, Aldeni Melo de Oliveira, Alessandra Mocellin Gerevini e Andreia Aparecida Guimarães Strohschoen (2017). «Diário de bordo: uma ferramenta metodológica para o desenvolvimento da alfabetização científica». Revista Tempos e Espaços em Educação, (10) 22: 119-132. DOI: 10.20952/revtee.v10i22.6429. 
Oliveira, Marilda Oliveira de (2014). «Diário de aula como instrumento metodológico da prática educativa». Revista Lusófona de Educação, (27) 1-27. Disponível em https://revistas.ulusofona.pt/index.php/rleducacao/article/view/4833.

PORLÁN, Rafael e José Martín (1997). El diario del profesor: Un recurso para la investigación en el aula. Sevilla: Díada.

SCALLON, Gérard (2015). Avaliação da aprendizagem numa abordagem por competências. Tradução de Juliana Vermelho Martins. Curitiba: PUCPRess.

VAlente, José Armando (2018). «A sala de aula invertida e a possibilidade do ensino personalizado: uma experiência com a graduação em midialogia». In Moran Bacich (org.), Metodologias ativas para uma educação inovadora: Uma abordagem téorico-prática. Porto Alegre: Penso.

Vosgerau, Dilmeire Sant'anna Ramos, Jelson Roberto de Oliveira, Cinthia Bittencourt Spricigo e Vida Martins. (2017). "O modelo de competências: Uma ferramenta para o planejamento da aprendizagem ativa». Disponível em https://bit. ly/2Vqqazx.

Zabalza, Miguel Angel (2007). Diários de aula: um instrumento de pesquisa e desenvolvimento profissional. Porto Alegre: Mediação.

\section{Sobre o autor}

Luiz Alberto Pereira Ribeiro e Mestre em Direito pela UEL. Doutor em Direito pela PUCPR. Professor Adjunto do Curso de Direito da PUCPR e da UEL. Especialista em GestãoeLiderançaUniversitária.Oseuendereçoelectrónicoéalberto.ribeiro@pucpr.br. (i) https://orcid.org./0000-0002-0313-1095. 
La Revista Pedagogía Universitaria y Didáctica del Derecho (RPUDD) es una publicación científica semestral que contribuye a la reflexión multidisciplinaria sobre pedagogía universitaria y didáctica del derecho, para la formación y consolidación de esta área de investigación; así como a la difusión de prácticas innovadoras en la enseñanza-aprendizaje del derecho considerando el contexto nacional e internacional. Es una publicación electrónica internacional con una codirección entre Brasil y Chile.

\author{
DIRECTORA \\ María Francisca Elgueta Rosas \\ Universidad de Chile \\ DIRECTOR \\ Renato Duro Dias \\ Universidad Federal de Rio Grande, Brasil \\ SITIO WEB \\ pedagogiaderecho.uchile.cl \\ CORREO ELECTRÓNICO \\ rpedagogia@derecho.uchile.cl \\ LICENCIA DE ESTE ARTÍ́CULO
}

Creative Commons Atribución Compartir Igual 4.0 Internacional

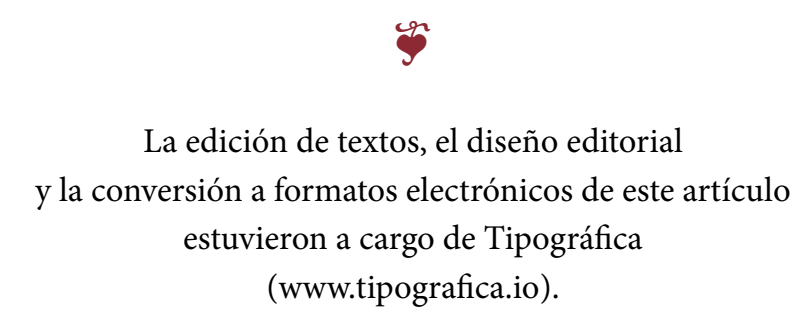

